\title{
Mechanical thrombectomy of acute ischemic stroke with a new intermediate aspiration catheter: preliminary results
}

\author{
Fabrizio Sallustio, ${ }^{1,2}$ Enrico Pampana, ${ }^{3}$ Alessandro Davoli, ${ }^{1}$ Stefano Merolla, ${ }^{3}$ \\ Giacomo Koch, ${ }^{1,2}$ Fana Alemseged, ${ }^{1}$ Marta Panella, ${ }^{1}$ Vittoria Carla D'Agostino, ${ }^{1}$ \\ Francesco Mori, ${ }^{1}$ Daniele Morosetti, ${ }^{3}$ Daniel Konda, ${ }^{3}$ Sebastiano Fabiano, ${ }^{3}$ \\ Marina Diomedi, ${ }^{1}$ Roberto Gandini ${ }^{3}$
}

${ }^{1}$ Comprehensive Stroke Center, Department of Systems Medicine, University of Tor Vergata, Rome, Italy ${ }^{2}$ Neurorehabilitation Unit, Santa Lucia Foundation, Rome, Italy ${ }^{3}$ Interventional Radiology and Neuroradiology, University of Tor Vergata, Rome, Italy

\section{Correspondence to} Dr Fabrizio Sallustio, Stroke Unit, Policlinico Tor Vergata, Viale Oxford 81, Rome 00133, Italy; fsall75@gmail.com

Received 8 December 2017 Revised 18 January 2018 Accepted 18 January 2018

Published Online First

8 February 2018
Check for updates

To cite: Sallustio $F$ Pampana E, Davoli A, et al. J Neurolntervent Surg 2018:10:975-977.

\section{ABSTRACT \\ Background and purpose To report clinical and procedural outcomes of acute ischemic stroke patients after endovascular treatment with the new thromboaspiration catheter AXS Catalyst 6.}

Methods Patients with anterior and posterior circulation stroke were selected. Successful reperfusion defined as a Thrombolysis in Cerebral Infarction (TICl) score $\geq 2 \mathrm{~b}$ and 3-month functional independence defined as a modified Rankin Scale $(\mathrm{mRS}) \leq 2$ were the main efficacy outcomes. Symptomatic intracranial hemorrhage and mortality were the main safety outcomes.

Results 107 patients were suitable for analysis. Mean age was 73.18 12.62 year and median baseline NIHSS was 17 (range: 3-32). The most frequent site of occlusion was the middle cerebral artery (MCA) (60.7\%). $76.6 \%$ of patients were treated with AXS Catalyst 6 alone without the need for rescue devices or thromboaspiration catheters. Successful reperfusion was achieved in $84.1 \%$, functional independence in $47.6 \%$, symptomatic intracranial hemorrhage occurred in $3.7 \%$, and mortality in $21.4 \%$.

Conclusions Endovascular treatment with AXS Catalyst 6 proved to be safe, technically feasible, and effective. Comparison analyses with other devices for mechanical thrombectomy are needed.

\section{INTRODUCTION}

One of the main lessons we have learned from recent endovascular stroke trials is that type of neurothrombectomy device matters. ${ }^{1}$ In 2012 current generation devices, the so-called stentrievers, were developed. Two of them have been deeply investigated in randomized controlled trials and large registries: Solitaire FR Revascularization Device (ev3, Irvine, California) and Trevo Retriever (Stryker Neurovascular, Fremont, CA, USA). ${ }^{2-4}$ New systems for clot aspiration combined to direct aspiration first-pass technique (ADAPT) ${ }^{5}$ have been also examined such as the 6F SOFIA plus catheter (MicroVention, Tustin, CA, USA) and the X Penumbra ACE catheters (Penumbra Inc., Alameda, CA, USA). ${ }^{67} \mathrm{~A}$ new catheter, the AXS Catalyst 6 (Stryker Neurovascular, Mountain View, CA, USA) represents a distal access catheter, originally designed for facilitating fast revascularization with Trevo retriever, able to navigate tortuous anatomy due to a 14 $\mathrm{cm}$ distal zone combined with a supportive proximal shaft (figure 1). The aim of this study was to report procedural and clinical results of endovascular treatment of large vessel stroke (LVS) with the ADAPT technique by means of AXS Catalyst 6 .

\section{MATERIALS AND METHODS \\ Patients' selection}

Patients with LVS of anterior or posterior circulation treated with the ADAPT technique by means of AXS Catalyst 6 as first approach were collected from our prospective endovascular stroke registry. Inclusion criteria were: groin puncture within 8 hours from symptom onset; pre-stroke modified Rankin Scale $(\mathrm{mRS}) \leq 2$; and available 3-month follow-up. When indicated, intravenous thrombolysis was administered within 4.5 hours of stroke onset and continued during endovascular procedure. ${ }^{8}$

\section{Mechanical thrombectomy}

Procedures were performed under conscious sedation or general anesthesia. Via transfemoral access, an 8 Fr long sheath (Neuron MAX 0.88 [Penumbra Inc., Alameda, CA, USA] or Infinity [Stryker Neurovascular, Mountain View, CA, USA]) was placed in the distal common carotid artery or in the proximal internal carotid artery (ICA) of the affected side as distally as possible or in patent or larger vertebral artery in case of posterior circulation occlusion in order to achieve the most stable access. The AXS Catalyst 6 was then advanced to the site of occlusion mostly alone or over a 0.014 neurowire (Transend or Synchro2 [Stryker Neurovascular, Mountain View, CA, USA]), and, in case of tricky passage through the ophthalmic ICA over 0.021 or 0.027 microcatheters or by means of a dedicated coaxial Offset catheter (Stryker Neurovascular, Mountain View, CA, USA) developed to facilitate intermediate catheter ophthalmic passage. After the Catalyst 6 catheter was positioned with the catheter tip close to the proximal part of the thrombus, microwire and microcatheter were removed when possible and aspiration using a vacuum pump or a $20-60 \mathrm{~mL}$ syringe was started. As soon as no flow was noted within the aspiration system, the catheter was slowly advanced to ensure 


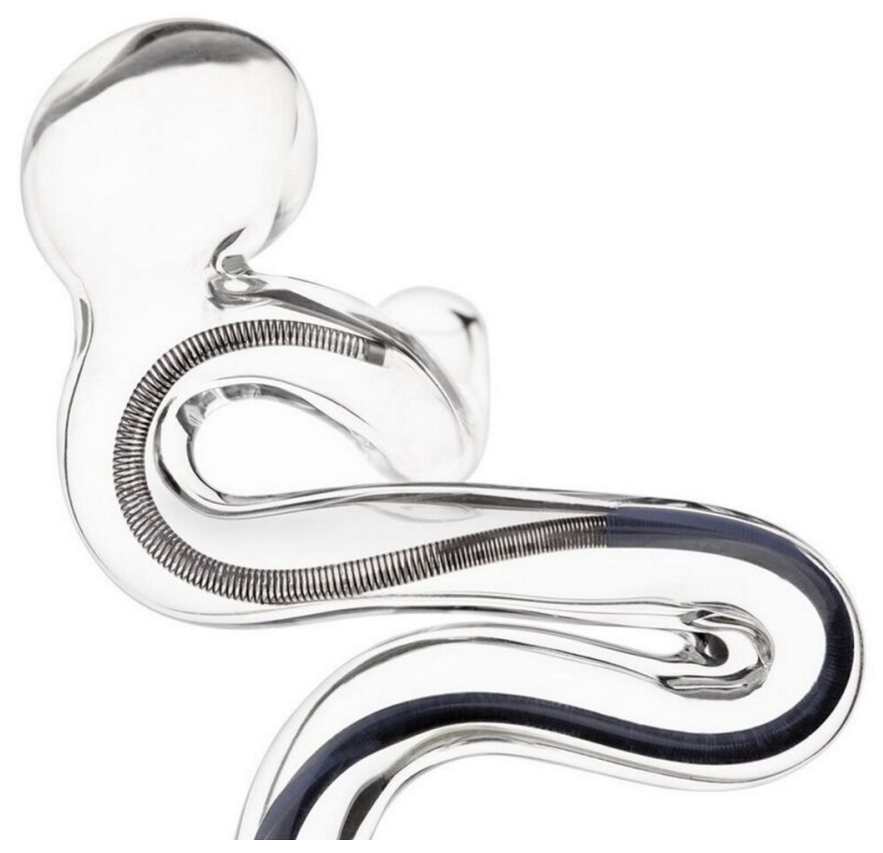

Figure 1 The AXS Catalyst 6 (Stryker Neurovascular, Mountain View, CA, USA) consists of a $14 \mathrm{~cm}$ distal zone combined with a supportive proximal shaft.

solid engagement with the thrombus and aspiration continued during Catalyst removal until blood was obtained in the aspiration line or total removal with additional aspiration from the long sheath in case of blood absence. In case of incomplete or failed revascularization, further attempts were repeated usually with the same Catalyst 6 and sometimes with different aspiration catheters (Penumbra catheters) or stentriever (Trevo or Revive) at the discretion of the operator.

\section{Assessment of clinical and imaging outcomes}

The main efficacy outcomes were successful reperfusion defined as a Thrombolysis in Cerebral Infarction (TICI) ${ }^{9}$ score $\geq 2 b$ and 3 -month functional independence defined as a $\mathrm{mRS} \leq 2$. The main safety outcomes were symptomatic intracranial hemorrhage (sICH) defined as an hemorrhage associated with an increase of at least 4 points in the National Institute of Health Stroke Scale $(\mathrm{NIHSS})^{10}$ and mortality $(\mathrm{mRS}=6)$. Secondary outcomes included any intracranial bleeding, complete reperfusion $(\mathrm{TICI}=3), 24$ hour clinical improvement defined as a reduction of at least 4 points in the NIHSS or an NIHSS of 0,24 hours after symptom onset. The study was approved by the local ethical committee (15161/2016). Informed consent was obtained from all patients or their relatives.

\section{RESULTS}

Based on inclusion criteria, we analyzed the period between the first and the last treatment with Catalyst 6 and available 3-month follow-up. From March 2016 through June 2017, out of 234 patients, 108 were treated with other devices as first approach, two were excluded because of hostile aortic arch anatomy and impossibility to reach the target vessel before any device was employed, and 17 missed 3-month follow-up leaving 107 patients for final analysis. Table 1 reports demographics and baseline characteristics.

Posterior circulation stroke accounted for $10 \%$ of the study population. Mean age was $73.18 \pm 12.62$ year, $57.9 \%$ were female, $42.1 \%$ were male and $96.1 \%$ had a pre-stroke mRS 0
Table 1 Demographics and baseline clinical and imaging characteristics

\begin{tabular}{|ll|}
\hline No. of patients & 107 \\
\hline Age (ys) mean \pm SD & $73.18 \pm 12.62$ \\
\hline Female (\%) & $62(57.9)$ \\
\hline Pre-stroke mRS 0-1 (\%) & $103(96.2)$ \\
\hline NIHSS median (range) & $17(3-32)$ \\
\hline Intravenous thrombolysis (\%) & $67(62.6)$ \\
\hline Site of arterial occlusion (\%) & \\
\hline Tandem & $27(25.2)$ \\
\hline Middle cerebral artery & $65(60.7)$ \\
\hline Terminal internal carotid artery & $2(1.8)$ \\
\hline T occlusion & $3(2.8)$ \\
\hline Posterior circulation & $10(9.3)$ \\
\hline TOAST (\%) & $61(57)$ \\
\hline Cardioembolic & $28(26.1)$ \\
\hline Large artery & $14(13)$ \\
\hline Undetermined & $4(3.7)$ \\
\hline Other determined
\end{tabular}

or 1 indicating no previous disability. Median baseline NIHSS was 17 (range: 3-32). Intravenous thrombolysis was used in $67(62.6 \%)$ patients (65 full-dose and two low-dose). The most frequent site of occlusion was the middle cerebral artery (MCA) (60.7\%) while the most frequent stroke etiology resulted to be cardioembolic (57\%). As shown in table 2 a small part of the study population was treated under general anesthesia (13\%); 76.6\% of patients were treated with AXS Catalyst 6 alone without the need for rescue devices or thromboaspiration catheters. Median procedural time (between groin puncture and reperfusion) and symptoms onset to reperfusion time of all 107 thrombectomy procedures were 40 (range: 10-148) and 272 (range: 109-540) minutes, respectively. Successful reperfusion was achieved in $84.1 \%$, functional independence in $47.6 \%$, sICH occurred in $3.7 \%$, and mortality in $21.4 \%$. When considering the 82 procedures performed with AXS Catalyst 6 alone the rate of successful reperfusion was 90.2\%, functional independence was obtained in $52.4 \%$, sICH occurred in $2.4 \%$, and mortality in $13.4 \%$. Procedural complications included a perforation in the distal MCA after employment of stentriever (3-month $\mathrm{mRS}=0$ ) and a distal embolization treated with employment of 4 MAX penumbra catheter $(3$-month $\mathrm{mRS}=6)$.

\section{DISCUSSION}

This is the first report of a large prospective series of patients undergoing mechanical thrombectomy with the AXS Catalyst 6. The choice of this catheter was encouraged by its higher trackability and reduced costs when compared to other intermediate aspiration catheters and stentriever technology. This is of relevance also in light of the recent results of the Contact Aspiration vs Stent Retriever for Successful Revascularization (ASTER) study showing no differences in efficacy and safety outcomes between stentriever and contact-aspiration thrombectomy. ${ }^{11}$ Our data suggest that the AXS Catalyst 6 is technically feasible, safe, and effective. Median procedural time was 40 minutes which is similar to the time reported for Solitaire in the STRATIS Registry. ${ }^{4}$ Successful reperfusion was achieved in $84.1 \%$ in the overall study population and in $90.2 \%$ of patients treated with 
Table 2 Procedural characteristics and outcome data

\begin{tabular}{|c|c|c|c|}
\hline & Overall $(n=107)$ & $\begin{array}{l}\text { Catalyst } 6 \\
(\mathrm{n}=82 ; 76.6 \%)\end{array}$ & $\begin{array}{l}\text { Catalyst } 6 \text { plus } \\
\text { additional } \\
\text { devices } \\
(n=25 ; 23.4 \%)\end{array}$ \\
\hline General anesthesia (\%) & $14(13)$ & $10(12.1)$ & $4(16)$ \\
\hline I.A. thrombolysis (\%) & $2(1.8)$ & 0 & $2(8)$ \\
\hline $\begin{array}{l}\text { No of passes } \\
\text { median (range) }\end{array}$ & $2(1-11)$ & $2(1-10)$ & $4(2-11)$ \\
\hline $\begin{array}{l}\text { Procedural time } \\
\text { median (range) }\end{array}$ & $40(10-148)$ & $39(10-110)$ & $66(30-148)$ \\
\hline $\begin{array}{l}\text { Onset to reperfusion time } \\
\text { median (range) }\end{array}$ & $272(109-540)$ & $276(109-540)$ & $265(185-316)$ \\
\hline Successful reperfusion (\%) & $90(84.1)$ & $74(90.2)$ & $16(64)$ \\
\hline Complete reperfusion (\%) & $68(63.5)$ & $58(70.7)$ & $10(40)$ \\
\hline Overall reperfusion (\%) & $101(94.3)$ & $80(97.5)$ & $21(84)$ \\
\hline $\begin{array}{l}\text { Unsuccessful } \\
\text { reperfusion (\%) }\end{array}$ & $6(5.6)$ & $2(2.4)$ & $4(16)$ \\
\hline $\begin{array}{l}\text { Any intracranial } \\
\text { hemorrhage (\%) }\end{array}$ & $31(28.9)$ & $22(26.8)$ & $9(36)$ \\
\hline $\begin{array}{l}\text { Symptomatic intracranial } \\
\text { hemorrhage }(\%)\end{array}$ & $4(3.7)$ & $2(2.4)$ & $2(8)$ \\
\hline $\begin{array}{l}\text { 24-hour clinical } \\
\text { improvement (\%) }\end{array}$ & $56(52.3)$ & $51(62.1)$ & $5(20)$ \\
\hline $\begin{array}{l}\text { Modified Rankin } \\
\text { Scale } \leq 2(\%)\end{array}$ & $51(47.6)$ & $43(52.4)$ & $8(32)$ \\
\hline $\begin{array}{l}\text { Modified Rankin } \\
\text { Scale } \leq 3(\%)\end{array}$ & $57(53.2)$ & $48(58.5)$ & $9(36)$ \\
\hline Mortality (\%) & $23(21.4)$ & $11(13.4)$ & $12(48)$ \\
\hline
\end{tabular}

Catalyst 6 alone without additional use of other devices. These findings are remarkable when considering a rate of $25 \%$ of tandem occlusion in our sample which are known to be a tricky lesion to be managed. ${ }^{12}$ Functional independence after 3 months occurred in $47.6 \%$ of patients despite a mean age of 73 years, symptomatic intracranial hemorrhage occurred in $3.7 \%$, and mortality was $21.4 \%$. These findings are similar to another study investigating Sophia plus catheter in acute ischemic stroke treatment. ${ }^{6}$ Complications in our study were rare, with an arterial perforation (not related to Catalyst 6 but to add-on employment of stentriever) and a distal embolization.

\section{SUMMARY}

AXS Catalyst 6 seems to be an efficient, safe, and technically feasible tool for mechanical thrombectomy. Further analyses comparing safety and efficacy outcomes and costs between Catalyst 6 and other thromboaspiration catheters or stentrievers seem to be worthwhile.

Contributors FS: conception of the work, acquisition and interpretation of data; drafting the work; final approval; accountable for all aspects. EP: design of the work; drafting the work; revising the work for important intellectual content; final approval; accountable for all aspects. AD: acquisition and analysis of data; drafting the work; final approval; accountable for all aspects. SM: conception of the work, acquisition and interpretation of data; final approval; accountable for all aspects. GK: acquisition and interpretation of data; revising the work; final approval; accountable for all aspects. FA: acquisition and interpretation of data; revising the work; final approval; accountable for all aspects. MP: acquisition and interpretation of data; revising the work; final approval; accountable for all aspects. VCA: acquisition and interpretation of data; revising the work; final approval; accountable for all aspects. FM: acquisition and interpretation of data; revising the work; final approval; accountable for all aspects. DM: acquisition and interpretation of data; revising the work; final approval; accountable for all aspects. DK: acquisition and interpretation of data; revising the work; final approval; accountable for all aspects. SF: acquisition and interpretation of data; revising the work; final approval; accountable for all aspects. MD: conception of the work, interpretation of data; revising the work for important intellectual content; final approval; accountable for all aspects. RG: design of the work; analysis and interpretation of data; revising the work for important intellectual content; final approval; accountable for all aspects.

Funding This work was supported by the Italian Ministry of Health (RF-201302358679).

Competing interests None declared.

Patient consent Obtained.

Ethics approval Local Ethics Committee.

Provenance and peer review Not commissioned; externally peer reviewed.

Data sharing statement Reasearch data will be available for sharing on request in the respect of Local Ethic Committee rules.

(c) Article author(s) (or their employer(s) unless otherwise stated in the text of the article) 2018. All rights reserved. No commercial use is permitted unless otherwise expressly granted.

\section{REFERENCES}

1. Berkhemer $O A$, Fransen $P S$, Beumer $D$, et al. A randomized trial of intraarterial treatment for acute ischemic stroke. N Engl J Med 2015;372:11-20.

2. Saver JL, Jahan $\mathrm{R}$, Levy El, et al. Solitaire flow restoration device versus the Merci Retriever in patients with acute ischaemic stroke (SWIFT): a randomised, parallelgroup, non-inferiority trial. Lancet 2012;380:1241-9.

3 Nogueira RG, Lutsep HL, Gupta R, et al. Trevo versus Merci retrievers for thrombectomy revascularisation of large vessel occlusions in acute ischaemic stroke (TREVO 2): a randomised trial. Lancet 2012:380:1231-40.

4 Mueller-Kronast NH, Zaidat 00, Froehler MT, et al. Systematic Evaluation of Patients Treated With Neurothrombectomy Devices for Acute Ischemic Stroke: Primary Results of the STRATIS Registry. Stroke 2017;48:2760-8.

5 Gory B, Armoiry X, Sivan-Hoffmann R, et al. A direct aspiration first pass technique for acute stroke therapy: a systematic review and meta-analysis. Eur J Neurol 2018;25:284-92.

6 Möhlenbruch MA, Kabbasch C, Kowoll A, et al. Multicenter experience with the new SOFIA Plus catheter as a primary local aspiration catheter for acute stroke thrombectomy. J Neurointerv Surg 2017;9:1223-7.

7 Hu YC, Stiefel MF. Force and aspiration analysis of the ADAPT technique in acute ischemic stroke treatment. J Neurointerv Surg 2016;8:244-6.

8 Sallustio F, Koch G, Di Legge S, et al. Intra-arterial thrombectomy versus standard intravenous thrombolysis in patients with anterior circulation stroke caused by intracranial arterial occlusions: a single-center experience. J Stroke Cerebrovasc Dis 2013;22:e323-e331.

9 Zaidat 00, Yoo AJ, Khatri P, et al. Recommendations on angiographic revascularization grading standards for acute ischemic stroke: a consensus statement. Stroke 2013;44:2650-63.

10 Hacke W, Kaste M, Fieschi C, et al. Intravenous thrombolysis with recombinant tissue plasminogen activator for acute hemispheric stroke. The European Cooperative Acute Stroke Study (ECASS). JAMA 1995;274:1017-25.

11 Lapergue B, Blanc R, Gory B, et al. Effect of Endovascular Contact Aspiration vs Stent Retriever on Revascularization in Patients With Acute Ischemic Stroke and Large Vessel Occlusion: The ASTER Randomized Clinical Trial. JAMA 2017;318:443-52.

12 Sallustio F, Motta C, Koch G, et al. Endovascular stroke treatment of acute tandem occlusion: a single-center experience. J Vasc Interv Radiol 2017;28:543-9. 